\title{
Introducing a new method to determine rivers' ecological water requirement in comparison with hydrological and hydraulic methods
}

\author{
A. Shokoohi • M. Amini
}

Received: 30 September 2012/Revised: 21 June 2013/Accepted: 21 October 2013/Published online: 20 November 2013

(C) Islamic Azad University (IAU) 2013

\begin{abstract}
The absence of a rational, comprehensive, flexible and easy to use method with minimum data requirement to determine rivers' environmental flow requirements is the main motivation for this research. Based on the microhabitat preferences of index species, hydrological (the Tennant and $Q_{95}$ ) and hydraulic methods for determining the environmental flow requirement (EFR) are compared. Using an ad hoc procedure, the important species of a river at the southern part of the Caspian Sea in Iran were distinguished, and the discharges to maintain the microhabitat (depth and velocity) in critical months were calculated. The observed differences between the index species' required velocity and depth and those suggested by the Tennant method emphasize the importance of the rivers morphological properties for this method application. Allocating EFR by the Tennant and $Q_{95}$ methods would degrade the aquatic life. The EFR determined by the hydraulic method is equal to $95 \%$ of the average annual discharge, which could maintain the ecological habitat in good situation, but may provoke a conflict in the region. The Tennant, $Q_{95}$ and hydraulic methods allocate EFR as 14,36 and $79 \%$ of the annual flow volume, respectively. Developing a new combined method based on using the
\end{abstract}

Electronic supplementary material The online version of this article (doi:10.1007/s13762-013-0404-z) contains supplementary material, which is available to authorized users.

A. Shokoohi $(\bowtie)$

Water Resources Engineering, Faculty Engineering and

Technology, Imam Khomeini International University,

Qazvin, Iran

e-mail: shokoohi@eng.ikiu.ac.ir

M. Amini

Water Engineering Department, Imam Khomeini International

University, Qazvin, Iran hydraulic method's discharge for critical months and the Tennant method suggestion for the excellent condition in other months allocates $50 \%$ of the average annual discharge. This new method is a compromise between protecting environment and considering the water rights of rivers' flow consumers and is suggested specially for dry regions of the world.

Keywords Environmental index · Index species · Environmental discharge $\cdot$ Tennant $\cdot Q_{95} \cdot$ Hydraulic method $\cdot$ Combined method

\section{Introduction}

The world is experiencing a continuous increase in water demand, and this has intensified the complicated challenge between controlling rivers as a fundamental water resource for human communities and saving their ecosystem in an acceptable condition (IUNC 2000). Control of rivers, because of population increase, raising the level of public health and welfare and other things like global warming, has become a complicated task for governments. Flow regulation through dam construction is the most affecting factor in changing the hydrological regime of rivers. About 500 dams have been built around the world since 1980 (Petts 1996). While at the present time more than half of the world surface water has been captured by human, it is predicted that this interference to be increased to more than $70 \%$ by 2,025 (Postel 1995; Postel et al. 1996). There are more than 48,000 large dams in 140 countries (WCD 2000), and it is estimated that more than 800,000 small dams are operating throughout the world (McCully 1996). In dry and semi-dry countries like Iran, people use rivers water wherever it is possible, employing any types of tools 
other than dams like pump stations or traditional intakes, with a minimum and sometimes without any respect to aquatic life. In this regard, for reducing river water withdrawal environmental impacts, the science of environmental flow assessment is going to be considered more seriously in developing countries. At the present time, allocating a part of river discharge for flowing in main channel and flood plain to save some valuable ecosystem properties, known as environmental flow requirement (EFR), has been accepted in many countries (Arthington et al. 2000; Tharme 2003). In this regard, the main difference among countries is the accepted level of protection. While saving aquatic life is the major concern in some developed countries, allocating a minimum discharge as EFR is a great target for environmentalists in developing countries.

More than 207 methods for determining the EFR have been recorded in 44 countries (Tharme 2003). Tharme (1996, 2003) classified these methods into 4 main groups; (1) hydrological (historical flows), (2) hydraulic rating, (3) habitat simulation and (4) holistic. In all of these methods, there is an assumption that the relationships between flow, wetted perimeter and physical habitat distinguish the ecological condition of a river (Jowett 1997). The hydrological methods, which define the minimum EFR, are the most popular methods and include more than 61 types, i.e., $30 \%$ of the total existing methods (Tharme 2003). The first place among the hydrological methods belongs to the Tennant method which is used in at least 25 countries, and the second place goes to the $Q_{95}$ method which is based on flow duration curve (FDC) and is used in about 18 countries such as the UK, Hungary, Taiwan and Australia. The hydraulic methods, which relate river channel's hydraulic parameters to discharge, have been introduced for assessment of fish habitat (Marchand 2006). As a component, they have been used in the habitat simulation and holistic methods and include more than 23 different methods and are employed in about $11 \%$ of the EFR studies across the world. The best method of this category is the wetted perimeter which uses the wetted perimeter of rivers as a surrogate for fish habitat.

Developing and some developed countries, many of which located on the arid belt of the Earth, because of the lack of data and the cost of the required data preparation, do not use the habitat simulation or holistic method. The principal reason for this research is the existence of an ambiguity in the environmental water allocation policy in Iran. In Iran, approving the rule curve of a dam is dependent on the allocation of a minimum discharge as EFR by the Tennant method, which has been set as the official method according to the regulation issued by the Ministry of Energy of Iran in 2007. As will be described subsequently, this method was developed for special purposes in some parts of the USA and allocates environmental water requirements seasonally. Shokoohi and Hong (2011a, b) illustrated the consequences of employing this method for EFR allocation. With the help of historical flow data of a river in the north of Iran, they could show that the aquatic life of the studied river would be deteriorated with the prescription of the Tennant method, although it is the officially recommended method. They suggested the application of the hydraulic method as the most compatible one with the existing condition. Hydraulic methods are based on this assumption that saving rivers natural morphological condition is enough to solve the problem of minimum water requirement (Jowett 1997). Accordingly, there is no need to know anything about the existing species and the required conditions for living that could be misleading in some cases. Focusing on this deficiency, habitat simulation methods consider a specific species and after collecting the necessary data for saving its optimum habitat determine the EFR. The diversity, required time and cost for data preparation are important obstacles to use these methods everywhere especially in the developing countries (Hudson et al. 2003). For example, the required time for data preparation for PHABSIM is at least 2 years (DeFreitas 2008).

This research wants to find one or more index species and then defines the optimum microhabitat. The proposed procedure, while combining hydraulic and hydrological methods regarding their simplicity, tries to use the principals of habitat simulation methods and introduce a rational discharge as EFR with respect to the dynamics and real conditions of rivers.

In the present research, the hydrological and hydraulic methods are examined via introducing an index method. By recognizing the living creatures of a river and introducing a method to determine the index species, the required hydraulic and hydrological conditions are determined. With respect to the microhabitat preferences of the index species, the results of the Tennant, $Q_{95}$ and hydraulic method for EFR will be compared and the most compatible one is introduced. Finally, a new combined method is introduced as the best method in a challenging environment.

\section{Materials and methods}

\section{Hydraulic method}

As it was mentioned, the most important method in this category is the wetted perimeter method which has been used for fish rearing in some parts of the world like the USA and Australia (Richardson 1986). From Fig. 1, one can deduce that this method has a clear definition of the relationship between discharge and habitat (wetted 


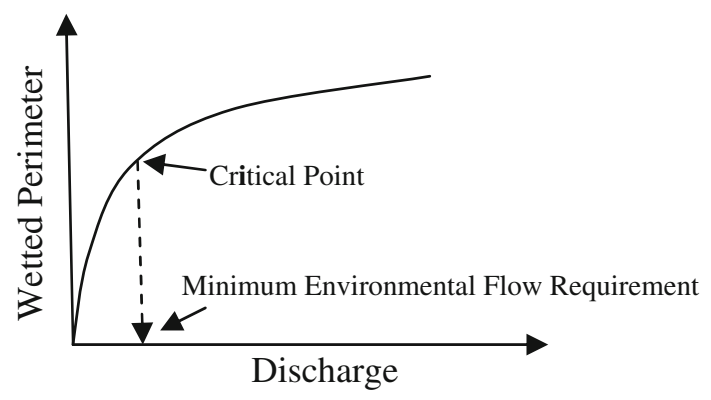

Fig. 1 Principles of the wetted perimeter method for EFR determination (shokoohi and Hong 2011a, b)

perimeter) (Suxia et al. 2006). At the critical point in Fig. 1, a little decrease in the discharge leads to a noticeable decline in the wetted perimeter (Annear and Conder 1984).

There are two different methods for finding the critical point; 1- the slope method and 2- the maximum curvature method (Gippel and Stewardson 1998). The relationship between wetted perimeter and discharge is a function of the geometry of river's cross sections, i.e., the way that the discharge is increased against the depth of water. These relationships between the two common shapes of cross sections, triangular and rectangular, are presented by Eqs. 1 and 2, respectively (Gippel and Stewardson 1998).

$P_{w}=a Q^{b}$

$P_{w}=a \ln Q+1$

In which " $P_{w}$ " is wetted perimeter in meter, " $Q$ " is discharge in $\mathrm{m}^{3} / \mathrm{s}$, " $a$ " and " $b$ " are the coefficients of the fitted curve.

In the slope method, Eq. 1 or 2 is differentiated with respect to $Q$ and is equaled to 1 in order to give the EFR, while in the maximum curvature method the deflection point of the fitted curve should be found. Curvature is a part of a curve where its direction is changed. Accordingly, the curvature is a function of the angle that the tangent to the curve at the point of deflection makes with horizon (Goodman, 1980). Eqs. 3 and 4 have been developed on this basis for rectangular and triangular shapes, respectively, in which $\mathrm{k}$ defines the curvature of the dischargewetted perimeter function. The maximum value of $\mathrm{k}$ could be achieved via the application of the critical point coordinates (Gippel and Stewardson 1998, Shokoohi and Hong 2011b).

$$
\begin{aligned}
& k=\frac{\frac{\mathrm{d}^{2} P}{\mathrm{~d} Q^{2}}}{\left[1+\left(\frac{\mathrm{d} P}{\mathrm{~d} Q}\right)^{2}\right]^{\frac{3}{2}}} \\
& k=\frac{\left|c b(b-1) Q^{b-2}\right|}{\left(1+\left(c b Q^{b-1}\right)^{2}\right)^{\frac{3}{2}}}
\end{aligned}
$$

Gippel and stewardson (1998) recognized the slope of curvature as the best method, while Shokoohi and Hong (2011a, b), after applying these methods in the Safarood River in Iran, preferred the maximum curvature method regarding the hydrological regime and ecological properties of the river. In this research, the maximum curvature method is used to derive the minimum environmental discharge.

Hydrological methods

In this paper, the two most popular hydrological methods, namely the Tennant and $Q_{95}$ methods are discussed.

\section{The Tennant method}

This method, which is sometimes called as the Montana method, was developed for 11 rivers in the states of Montana, Wyoming and Nebraska in the USA to determine appropriate discharge for saving fish-passing on the streams' beds. According to the observed data, a flow equal to $30 \%$ of average annual discharge is necessary to maintain proper width, depth and velocity of the stream (Tennant 1976).

The Tennant method's criteria for the EFR determination are based on the morphological properties of the experimental rivers; that is, this method is a regional method, which should be considered when using this method in other places. Primarily, the accepted criteria in the Tennant method reduce a fixed value from all of the flows regardless of low- or high-flow conditions, which could pose severe losses to the river environment during low-flow periods (Smakhtin et al. 2006).

\section{$Q_{95}$ method}

This method defines the EFR as a discharge which is flowing in rivers for $95 \%$ of total days (342 days) in a year. This flow can be read on a flow duration curve.

\section{Setting criteria for index species selection}

The most important habitat simulation methods use required hydraulic properties (depth and velocity) for a target or an index species to determine the EFR (Jowett, 1997). In most cases, because of the long life span and presence at the top of ecological pyramid, a type of fish is selected to be the index species. On this basis, waddle (2001) says that the existence of fish in a river is equal to the existence of healthy condition for living creatures. Some species are more sensitive and important than the others; therefore, it is necessary to find index species for the EFR determination. 
Table 1 Items used for determining the index species

\begin{tabular}{|c|c|c|}
\hline $\begin{array}{l}\text { Item } \\
\text { number }\end{array}$ & Definition & Value \\
\hline 1 & $\begin{array}{l}\text { The value corresponds to the international } \\
\text { conservation: The species that their names have } \\
\text { been recorded in the red list of the IUCN and } \\
\text { are endangered or facing a high risk of } \\
\text { becoming extinct }\end{array}$ & 9 \\
\hline 2 & $\begin{array}{l}\text { The value corresponds to the national } \\
\text { conservation: The species that are listed as } \\
\text { protected and are facing the risk of becoming } \\
\text { extinct (in the country) }\end{array}$ & 7 \\
\hline 3 & $\begin{array}{l}\text { The value corresponds to the status of being a } \\
\text { genetic resource for the country: The species } \\
\text { that are monolocale and endemic }\end{array}$ & 5 \\
\hline 4 & $\begin{array}{l}\text { The value corresponds to ecological importance: } \\
\text { The species that play a special role in the } \\
\text { regional aquatic ecosystem. For example, Algae } \\
\text { eaters that connect the top and bottom of the } \\
\text { food pyramid }\end{array}$ & 3 \\
\hline 5 & $\begin{array}{l}\text { The value corresponds to economic importance: } \\
\text { The species that are appropriate for economical } \\
\text { use }\end{array}$ & 2 \\
\hline 6 & $\begin{array}{l}\text { The value corresponds to fishing sport: The } \\
\text { species that are important for tourism and } \\
\text { development of the region }\end{array}$ & 1 \\
\hline
\end{tabular}

Regarding fish habitat, 48, 29 and $23 \%$ of the southern Caspian Sea fish are anadromous, saltwater and fresh water fish, respectively, while regarding their origin, 59, 24 and $17 \%$ of them are indigenous, non-indigenous and endemic, respectively.(Abdoli and Naderi 2008; Coad 2012).

The International Union for Conservation of Nature and Natural Resources (IUCN) has divided species into 7 categories according to their conservation condition: $1-$ critically endangered (CR), 2-vulnerable (VU), 3-endangered (EN), 4-near threatened (NT), 5-conservation dependent (CD), 6-least concern (LC), 7-data deficient (DD) (Abdoli and Naderi 2008). The third column in Table 2 shows the conservation status of existing species in the study area.

Regarding this fact that the index species depict the actual situation of river habitat, it is necessary to evaluate their value from different points of view. Here, we have used an ad hoc procedure, which have been used successfully for determining the Sefidroud River index species in the north of Iran (Gilan Regional Water Board 2009). In this method, 6 items is used to evaluate the importance or value of a species (Abdoli and Naderi 2008), and a number from 1 to 9 is assigned accordingly. Table 1 demonstrates the Items, definition of each item and associated values.
The index value for any species is calculated via Eq. 5: Index No. $=[$ international conservation value $(0$ or 1$) * 9]$

$$
\begin{aligned}
& +[\text { national conservation value }(0 \text { or } 1) * 7] \\
& +[\text { genetic resource value }(0 \text { or } 1) * 5] \\
& +[\text { ecological value }(0 \text { or } 1) * 3] \\
& +[\text { economic value }(0 \text { or } 1) * 2] \\
& +[\text { fishing sport value }(0 \text { or } 1) * 1]
\end{aligned}
$$

The top scores distinguish the index species.

Study region

The Kazemroud River in the southern part of the Caspian Sea in the North of Iran was chosen for the case study. This river flows from south to north and is one of the cases which are to be studied in a pilot comprehensive river engineering project in the western part of the Mazanderan province. There are digital maps for the river's watershed at the scale of 1:25,000 and for its cross sections at the scale of 1: 1,000 from the mouth of the river to a distance much far from the desired reach toward the Alborz Mountain. Figure 2 shows the Kazemroud River and its location.

\section{Hydrological data}

Hydrological data were gathered from a gauge station, called as Mashal abab, which has a limnigraph and a scale. This gauge is located at Zone 39 (UTM coordinate system) with the Easting $=508,530 \mathrm{~m}$ and Northing $=4,064,964 \mathrm{~m}$ and has been working since 1981 (Khazarab-Abenergy co. 2010). With the help of stage-discharge function of the gauging station, the Manning coefficient for the entire region was determined as $0.069-0.088$ with a mean of 0.077 for the main channel regarding the range of discharges used for evaluating the EFR. The concerned reach of the river has a length of about $10 \mathrm{~km}$. Figure 2 illustrates the study reach of the river. The Kazemroud River is a perennial river and water always flows through its fish passages even in summer months. Of course, this condition may be altered after constructing a proposed diversion dam in the upstream part of the river. The average annual discharge of the river at the Mashal abad is $2.37 \mathrm{~m}^{3} / \mathrm{s}$ and its maximum yield occurs during winter and spring, while summer contribution to the annual yield is limited to $18 \%$.

\section{Results and discussion}

Index species selection

As it was mentioned, 6 items were used to identify the index species for the Kazemroud River. Table 2 shows the 

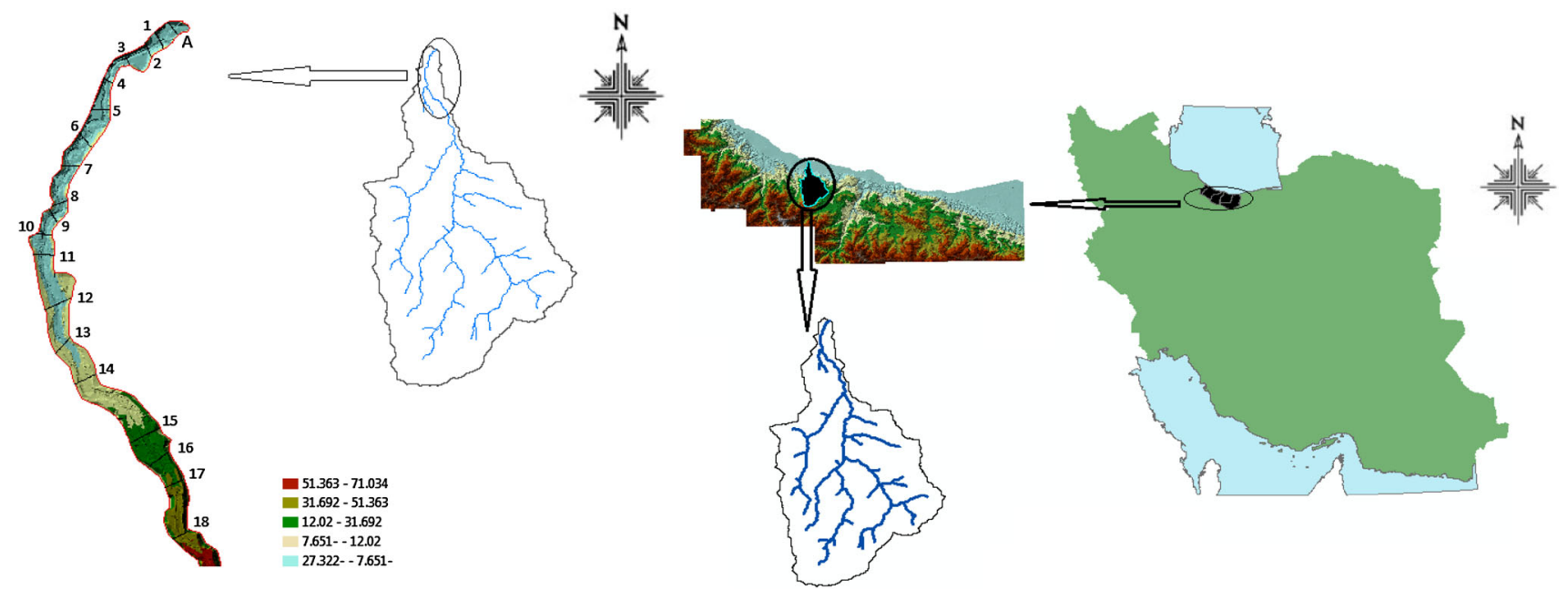

Fig. 2 Kazemroud River and its location

applicability of each item to the existing fish types in the river by giving 1 or 0 number to each of which.

The last column in Table 2 was calculated by Eq. 5 . As it is seen, a range of values between 3 and 14 was achieved for the index number. To distinguish the index species, it is necessary to define a lower limit for this number. According to the existing experiments, the lower threshold for index number could be calculated by adding $90 \%$ of the observed median to itself (Gilan Regional Water Board 2009). The median of index numbers for the fishes is 4 , then the lower limit of index number will be $4+(0.9 * 4)=7.6$. Accordingly in Table 2 , each value greater than this threshold was marked by an asterisk. Table 3 shows the index species and their important features necessary for the EFR study.

To determine the EFR, It is necessary to know the months of presence of the index species in the river. Table 3 shows these months.

\section{Assessment of index species microhabitat requirements}

In the last section, 4 index species were selected. By fixing the index species required depth as the initial value, determining the Manning coefficient and using the stage-discharge function of each cross section, one can calculate the discharge and flow velocity in any cross section. The results for 4 selected cross sections are illustrated in Table 4 . The column "Critical $Q$ " is the minimum monthly discharge available at the period of index species presence in the river, and the column "Min. $Q$ " is the discharge required to maintain the preferred depth in the specified cross section.

Among the index species, Luciobarbus capito-native is present in the river throughout the year. The minimum required discharge for this fish is about $30 \%$ of the average annual discharge. The minimum available monthly discharge occurs in August, which is greater than the required one. On this basis, one can say that the required discharge for providing the necessary conditions for living of this type of fish is always available in the entire river. There is such a condition for Caspiomyzon wagneri which is present in the river during March through May. In the period of the presence of this fish in the river, the least amount of discharge occurs in May. This minimum discharge is near to the average annual discharge, while $30 \%$ of which is enough for saving the habitat for this fish in a good condition. The critical discharge for the Alburnus chalcoides, which migrates for spawning into the river during March and lives there till June, is 1.36 cubic meter per second ( $60 \%$ of the annual discharge) which is enough to meet the $A$. chalcoides microhabitat preferences. But in this situation, the river condition is not appropriate for the $L$. capito and the critical discharge is not enough to meet the microhabitat requirements. This type of fish should live in the river from March to July, while the required discharge can be met just in May. The $L$. capito is facing the risk of becoming extinct (Abdoli and Naderi 2008). Many factors can be responsible for the fish extinction, but microhabitat bad condition can play an important role in this regard.

Results of the hydrological methods application

\section{The Tennant method}

Tennant used some assumptions for determining the EFR as a percent of average annual discharge. He supposed that for a flow equal to $10 \%$ of the average annual discharge, a depth of $30 \mathrm{~cm}$ and a velocity of $25 \mathrm{~cm} / \mathrm{s}$ could provide the minimum required condition for aquatic life. Tennant also stated that for $30 \%$ of the annual discharge, a depth of $45-60 \mathrm{~cm}$ and a range of velocity from 45 to $60 \mathrm{~cm} / \mathrm{s}$ could provide a 


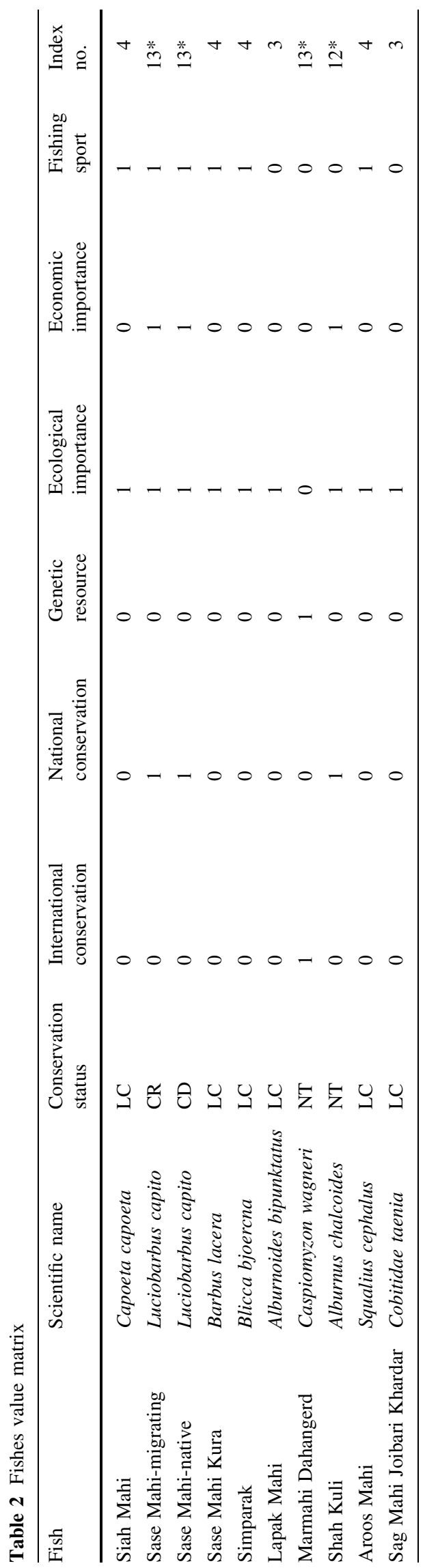

good to optimum condition for fish (Jowett 1997). For the two depths of 30 and $45 \mathrm{~cm}$, the river discharge was calculated at each cross section and presented in Table 5 .

In all sections (except section 8), both depths requires discharges more than the Tennant proposed percents $(10$ and $30 \%$ of the average annual discharge) for maintaining the minimum and good conditions. This issue reveals the fact that the morphological condition of the Kazemroud River is not compatible with that of the rivers where Tennant developed the method.

Table 6 presents the cross sections' depths and velocities resulted from the application of 10,30 and $60 \%$ of the annual discharge.

In Table 6 , it is clear that for $10 \%$ of the annual discharge, as the minimum EFR to save the aquatic life in the margin of existence, the required depth and velocity are not available for none of the index species. Frequency analysis of the historical data of the Kazemroud River gives the discharge in dry period with a 100 -year return period as 0.8 cubic meters per second which is greater than the minimum discharge proposed by the Tennant method. It is obvious that fixing such an amount of flow for a river that its morphological properties were formed by an annual discharge of $2.37 \mathrm{~m}^{3} / \mathrm{s}$ could cause many serious problems and endanger the aquatic life. The $30 \%$ flow is appropriate for both of the C. wagneri and $L$. capito-native, but endangers the A. chalcoides. The habitat of the A. chalcoides and $L$. capito could be saved just by providing 60 and $100 \%$ of the annual discharge, respectively.

$Q_{95}$ method

For the Kazemroud River, the $Q_{95}$ using the flow duration curve is equal to $0.85 \mathrm{~m}^{3} / \mathrm{s}$. This discharge is close to the Tennant $30 \%$ discharge; therefore, one can conclude that only the $C$. wagneri and $L$. capito-native are conserved and the two others will be confronted with some problems. The results show that the $Q_{95}$ is capable of introducing the minimum discharge during non-critical months, while during migrating months does not guarantee the existence of proper condition for all species. Shokoohi and Hong (2011b) applied this method for evaluating EFR in the Safaroud River, which is a perennial river in the southern Caspian Sea, and introduced this method as one of the most efficient methods for determining the minimum ecological discharge and stated that it could be a rival for the morphological-based methods. The present study shows that this conclusion about $Q_{95}$ capabilities when considering the biological factors could be misleading and is not correct everywhere.

\section{Hydraulic (wetted perimeter) method}

This method gives the minimum environmental discharge on the basis of morphological properties of rivers. By 
Table 3 Index species of Kazemroud River and some necessary information

\begin{tabular}{|c|c|c|c|c|c|}
\hline Species & $\begin{array}{l}\text { Period of } \\
\text { spawning }\end{array}$ & $\begin{array}{l}\text { Depth in non-critical } \\
\text { months }(m)\end{array}$ & $\begin{array}{l}\text { Depth in critical } \\
\text { months (m) }\end{array}$ & $\begin{array}{l}\text { Velocity } \\
(\mathrm{m} / \mathrm{s})\end{array}$ & $\begin{array}{l}\text { Conservation } \\
\text { status }\end{array}$ \\
\hline Caspiomyzon wagneri & $\begin{array}{c}\text { Late March- } \\
\text { early May }\end{array}$ & - & 0.3 & $0.5-0.8$ & NT \\
\hline $\begin{array}{l}\text { Luciobarbus } \\
\text { capito-native }\end{array}$ & All months & 0.3 & 0.3 & $0.4-0.8$ & $\mathrm{CD}$ \\
\hline Alburnus chalcoides & $\begin{array}{l}\text { Late March- } \\
\text { early June }\end{array}$ & - & 0.4 & $0.8-1.1$ & NT \\
\hline Luciobarbus capito & June-July & - & 0.5 & $0.8-1.1$ & $\mathrm{CR}$ \\
\hline
\end{tabular}

applying the maximum curvature method for rectangular channels (Eq. 3), the EFR and the essential microhabitat properties were calculated and presented in Table 7.

By comparing the results of the hydraulic method with the average annual discharge, one can conclude that except section 8, the calculated EFR is about $95 \%$ of the annual discharge that could provide proper conditions for all species in the river. As it is seen, the depth and velocity in all sections are in a range which in the Tennant method is considered to be optimum for aquatic life. It is useful to remember that the optimum condition in the Tennant method is provided by an EFR equal to $30 \%$ of the annual discharge which is greatly different from the achieved percent by the hydraulic method. On the basis of applying the hydraulic method and providing a discharge of $2.30 \mathrm{~m}^{3} / \mathrm{s}$ for all months, one can be confident that the Kazemroud River biological habitat will be protected and saved in its present condition. The diversion of water can be any amount greater than that of proposed by the hydraulic method.

\section{Developing a new combined method}

According to the achieved results, the EFR evaluated by the hydraulic method is the most rational one, but meanwhile a conflict between rationality and applicability could be observed. Figure 3 illustrates the allocated water for environment by the three mentioned methods. While the proposed minimum EFR by the hydrological methods is approximately equal to the severe drought condition in the river, the defined minimum EFR by the hydraulic method allocates $79 \%$ of the annual volume for saving the habitat that can be controversial in any region especially in a dry region. On the other hand, the calculated values show that in the non-critical months (from September to March), $30 \%$ of the annual discharge could preserve the habitat for the freshwater index species. According to the Tennant method, this discharge is placed in the "excellent" class. By using these facts, a new combined method is proposed that not only can preserve environment but also is rational and reduces the conflicts between rivals. According to this new method, which is called as the combined method, the
EFR is $95 \%$ of the average annual flow or the natural flow (each one that is smaller) from March to August and $30 \%$ of the annual flow for other months. In this situation, the allocated water for saving habitat by the combined method is equal to $50 \%$ of the total flow volume in a year, while for the Tennant, $Q_{95}$ and hydraulic method, it is 14,36 and $79 \%$, respectively.

\section{Conclusion}

Determining the Environmental flow requirement is a challenge especially in the developing countries. Among different methods, the Tennant method as a hydrological method, due to its simplicity and limited data requirement, is the most attracting one. Hydrological methods are inherently regional methods; that is, these methods need to be calibrated and validated for any new region. On this basis, using the Tennant method is facing with the risk of introducing wrong EFR because of its limitation of application. Preventing the release of household, industrial and agricultural effluents to rivers is not managed coherently in almost all developing countries, which in turn emphasizes the precision and compatibility of an EFR evaluation method with each river specifications (De Jalon 2003). In such circumstances, reducing the flowing water volume by a mistake could lead to a catastrophic condition for rivers and their living creatures. In this paper, it is shown that the Tennant method, which just for the sake of simplicity has been accepted as the official method for the EFR evaluation in Iran, could lead to an environmental catastrophe. In this regard, it is shown that the Tennant method, which was developed in the USA for some states like Nebraska, is completely dependent to the region where its criteria were developed and could not be used directly in the other parts of the world without finding morphological similarities. The last criteria could not be evaluated precisely, because Tennant (1976) has not reported the morphological properties of the studied rivers. One of the methods that can be regarded as a competitor for other methods and in some researches was realized to have the potential to be used as a 


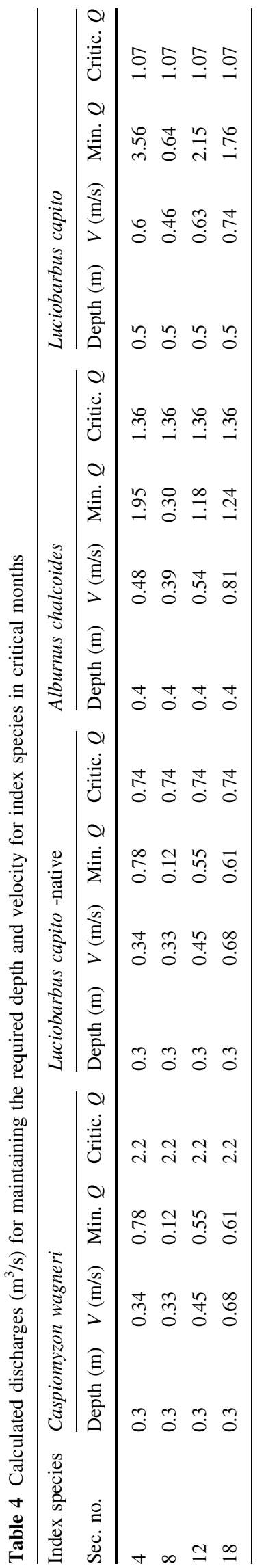

Table 5 Discharges of the river due to applying the Tennant method assumptions

\begin{tabular}{llllll}
\hline Section no. & \multicolumn{2}{l}{ Depth $=30 \mathrm{~cm}$} & & \multicolumn{2}{l}{ Depth $=45 \mathrm{~cm}$} \\
\cline { 2 - 3 } \cline { 5 - 6 } & $\underline{Q}\left(\mathrm{~m}^{3} / \mathrm{s}\right)$ & $V(\mathrm{~m} / \mathrm{s})$ & & $Q\left(\mathrm{~m}^{3} / \mathrm{s}\right)$ & $V(\mathrm{~m} / \mathrm{s})$ \\
\hline 4 & 0.34 & 0.78 & 0.54 & 2.71 \\
8 & 0.33 & 0.12 & 0.43 & 0.44 \\
12 & 0.45 & 0.55 & & 0.59 & 1.62 \\
18 & 0.68 & 0.61 & & 0.88 & 1.66 \\
\hline
\end{tabular}

surrogate for the Tennant method (Shokoohi and Hong $2011 \mathrm{a}, \mathrm{b})$ is the $Q_{95}$ method which is used in some developed/developing countries at the present time. Besides these two hydrological methods, there is a hydraulic method which by providing minimum information about the morphological properties of rivers, including their geometrical specifications, gives the EFR. This method in contrast to the hydrological methods does not have predefined criteria; therefore, in this sense, if one could classify the hydrological methods as static methods, the hydraulic method is a dynamic one. Shokoohi and Hong (2011a, b), with the help of historical data and rational judgments, have introduced the capabilities of this method for the EFR evaluation. In the present paper, the 3 aforementioned EFR evaluation methods have been tested by another tool. If one defines microhabitat by the depth and velocity of flow or at least considers these two hydraulic parameters as the most important component of a microhabitat, it is possible to use each of which as an indicator to compare the EFR evaluation methods. In this research, after recognizing the existing fish species in the southern Caspian Sea and by an ad hoc method, the index species were determined for a river as the case study. An interesting point in this research is using more than one species as index species. In this work, $C$. wagneri, $L$. capito-native, $L$. capito and A. chalcoides were distinguished to be the index species regarding 6 items including their international and national importance, being a genetic resource, their place in food pyramid, economic and regional importance.

According to the achieved results, the proposed Tennant microhabitat conditions which are associated with the EFRs equal to 10 and $30 \%$ of the average annual discharge cannot be met in the study river. The required discharge for conserving microhabitat in the study river is about two or three times greater than the calculated one by the Tennant method. From morphological point of view, this emphasizes the most critical shortcoming of the Tennant method as to be a regional not a universal method. The results show that the study river is not similar to the rivers studied by Tennant; therefore, it is not expected the Tennant method could give a proper value for the EFR. In this regard, the 


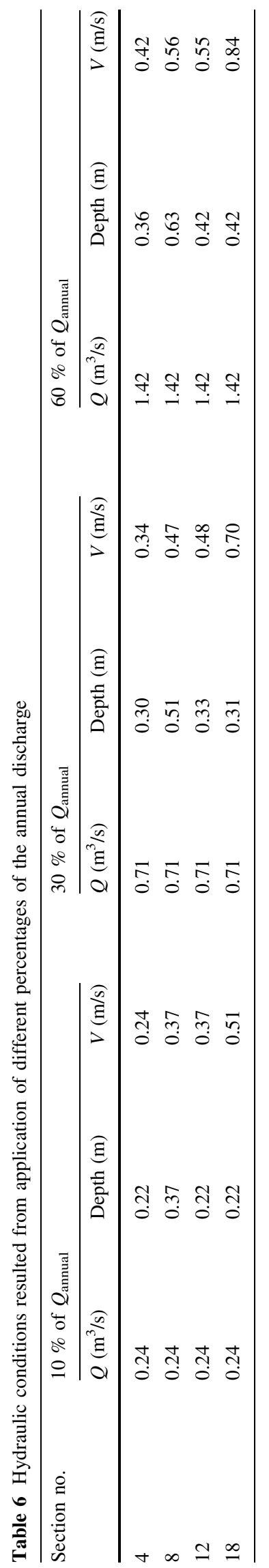

Table 7 Wetted perimeter method evaluations of the EFR and hydraulic parameter

\begin{tabular}{llll}
\hline Section no. & Depth $(\mathrm{m})$ & $\mathrm{V}(\mathrm{m} / \mathrm{s})$ & EFR $\left(\mathrm{m}^{3} / \mathrm{s}\right)$ \\
\hline 4 & 0.42 & 0.51 & 2.24 \\
8 & 0.65 & 0.57 & 1.56 \\
12 & 0.51 & 0.64 & 2.26 \\
18 & 0.54 & 0.81 & 2.30 \\
\hline
\end{tabular}

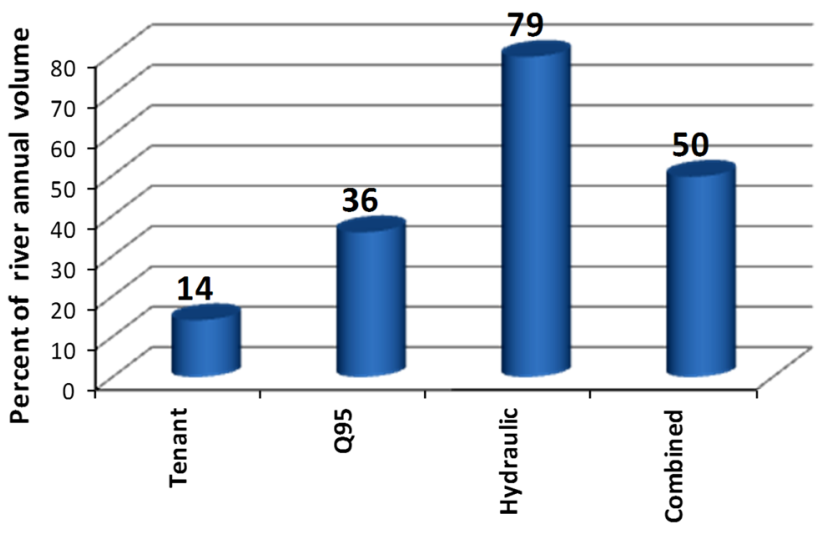

Fig. 3 The combined method water allocation in comparison with the their methods

$10 \%$ of the annual discharge in the Tennant method can destroy the ecological conditions for all index species. While the $30 \%$ of the annual discharge in the Tennant method can save the habitat of the two native index species, the $60 \%$ of the annual discharge can conserve 3 out of 4 index species, and the annual discharge can conserve all of the species in the study river. Henceforth, the Tennant method cannot be used for EFR evaluation in the study area. This confirms the limited past reports on the necessity of reforming the Tennant method for any new region instead of its direct application.

The $Q_{95}$ method suggests a discharge equal to $36 \%$ of the annual discharge, which is only enough for 2 out of 4 index species. Some researchers have suggested this method as a substitute for the Tennant method, but the achieved results in the present research raises some doubts about this declaration.

For the study area, the hydraulic method (the wetted perimeter method) determined the EFR as $95 \%$ of the annual discharge which preserve all creatures in the river. It is a good result from environmental conservation point of view, but may provoke or intensify the conflict among the users of water especially when water shortage is a big problem. Furthermore, in this method, the EFR is identical for rivers with the same hydraulic condition, while they are home for different species with different habitat requirements. The solution to this deficiency is using the holistic methods that because of many reasons such as wide extent of required data, long span of time necessary to collect 
them (2-5 years) and limited financing of projects (Tharme 2003) could not be employed in developing countries like Iran. To overcome the shortcomings of the mentioned methods for the EFR determination, a new combined method was proposed. The present research and its proposed combined method is unique and the first one in this category which integrate the vigorous points of the aforementioned methods. While it enjoys the simple but precise structure of the hydraulic methods, it uses the clear thresholds of the hydrological methods and finally incorporates the real habitat conditions into the model body to tune the EFR. In this regard, between all of the physical parameters to simulate the habitat, the new combined method employs the most important and easily calculated parameters: velocity and depth. One of the most valuable points of the proposed combined method is the limited field works and using desktop activities with the help of literature reviews for determining the index species, which is very important for river-oriented engineering projects.

The combined method suggests $95 \%$ of the average annual flow or the natural flow (each one that is smaller) for critical months and $30 \%$ of the annual flow for the other months. In this situation, the allocated water for saving habitat is equal to $50 \%$ of the total flow volume in a year, while the Tennant, $Q_{95}$ and hydraulic methods allocate 14,36 and $79 \%$ of the annual volume, respectively. It is obvious that the results of the new combined method not only save the environment, but also, because of setting a fair share between rivals, is a solution to the water allocation conflict in any region facing with water shortfall.

Acknowledgments This research has been supported by the Deputy of Research \&Technology of Imam Khomeini International University under the Grant No. 751036-91.

\section{References}

Abdoli A, Naderi M (2008) Fish bio-diversity in the southern Caspian Sea. Abzian Elmi, Tehran, p 237

Annear TC, Conder AL (1984) Relative bias of several fisheries instream flow methods. North Am J Fish Manag 4:531-539

Arthington AH, Brizga SO, Choy SC, Kennard MJ, Mackay SJ, Cosker RO, Ruffini JL, Zalucki JM (2000) Environmental flow requirements of the Brisbane River downstream of Wivenhoe Dam. South East Queensland Water Corporation Ltd and Centre for Catchment and In-Stream Research, Qeensland, p 539

Coad BW (2012) (Last visited). Freshwater fishes of Iran, online available at (www.briancoad.com)

De Jalon DG (2003) The Spanish experience in determining minimum flow regimes in regulated streams. Can Water Resour J 28(2):1-14

DeFreitas GK (2008) Methods and tools for defining environmental flows. Central Savannas Conservation Program, Brasilia

Gilan Regional Water Board (2009) An overview report on environmental requirements in the Qazalozan-Sefidroud integrated water resources planning study. Gilan Regional Water Corporation, Gilan, p 48
Gippel CJ, Stewardson MJ (1998) Use of wetted perimeter in defining minimum environmental flows. Regul Rivers: Res Manag 14:53-67

Goodman AW (1980) Analytical geometry and the calculus, 4th edn. Macmillan Publishing Co. Inc., New York 997

Hudson HR, Byrom AE, Chadderton WL (2003) A critique of IFIMinstream habitat simulation in the New Zealand context, Department of Conservation Wellington, New Zealand. A Project report for science for conservation No. 231

IUCN (World Conservation Union). (2000). Vision for Water and Nature. A World Strategy for conservation and sustainable management of water resources in the 21 st Century. IUCN, Gland, Switzerland and Cambridge, UK, p 52

Jowett IG (1997) Instream flow methods: a comparison of approaches. Regul Rivers: Res Manag 13:115-127

Khazarab_Abenergy (2010) Comprehensive project of West of Mazandaran river engineering project, Hydrology report. Coconsulting engineers Khazarab-Ab Energy Mohit, Mazandaran Regional Water Corporation, Ministry of Energy of Iran, p 280

Marchand MD (2006). Environmental flow requirements for rivers :An integrated approach for river and coastal zone management. W1/Delft hydraulics Report No. Z2850

McCully P (1996) Silenced rivers: the ecology and politics of large dams. ZED books, London, p 359

Petts GE (1996) Water allocation to protect river ecosystems. Regul Rivers: Res Manag 12:353-365

Postel SL (1995) Where have all the rivers gone? World Watch Mag 8(3):9-19

Postel SL, Daily GC, Ehrlich PR (1996) Human appropriation of renewable freshwater. Science 271:785-788

Richardson BA (1986) Evaluation of instream flow methodologies for freshwater fish in New South Wales. In: Campbell IC (ed) Stream protection, the management of rivers for instream uses. Water Studies Centre, Chisholm Institute of Technology, Caulfield, pp 143-167

Shokoohi A, Hong Y (2011a) Using hydrologic and hydraulically derived geometric parameters of perennial rivers to determine minimum water requirements of ecological habitats (case study: Mazandaran Sea Basin-Iran). Hydrol Process 25:3490-3498

Shokoohi A, Hong Y (2011b) Determining the minimum ecological water requirements in Perennial rives using morphological parameters. J Environ Stud 37(58):117-128

Smakhtin VU, Shilpakar RL, Hughes DA (2006) Hydrology-based assessment of environmental flows: an example from Nepal. Hydrol Sci 51(2):207-222

Suxia L, Xingguo M, Jun X, Changming L, Zhonghui L, Baohui M, Lina $J$ (2006) Estimating the minimum in-stream flow requirements via wetted perimeter method based on curvature and slope techniques. J Geog Sci 16(2):242-250

Tennant DL (1976) Instream flow regimens for fish, wildlife, recreation and related environmental resources. Fisheries 1(4):6-10

Tharme RE (1996) Review of international methodologies for the quantification of the instream flow requirements of rivers. Water law review final report for policy development for the Department of Water Affairs and Forestry, Pretoria. Freshwater Research Unit, University of Cape Town, South Africa, p 116

Tharme RE (2003) A global perspective on environmental flow assessment: emerging trends in the development and application of environmental flow methodologies for rivers. River Res Appl 19:397-442

Waddle T (2001) PHABSIM for Windows: user's manual and exercise. Fort Collins, CO, US Geological Survey, p 288

World Commission on Dams (WCD) (2000) Dams and Development. A New Framework for Decision-making. The report of the World Commission on Dams. Earthscan Publications, London, p 17 